\title{
$\pi$-Stacking interactions between G-quartets and circulenes: A computational study
}

\author{
A K JISSY, J H V RAMANA and AYAN DATTA* \\ School of Chemistry, Indian Institute of Science Education and Research Thiruvananthapuram, \\ CET Campus, Thiruvananthapuram 695016, India \\ e-mail: ayan@iisertvm.ac.in
}

\begin{abstract}
Structures of planar and bowl-shaped circulenes as well as their stacks with G-quartet (G4) have been investigated through dispersion-corrected Density Functional Theory (DFT-D). The binding energies are substantial $\sim 10 \mathrm{kcal} / \mathrm{mol}$ with $\mathrm{d} \sim 3.5 \AA$ between the stacking rings. The calculations show that $\mathrm{G} 4$ binds much more effectively to planar circulenes as compared to bowl shaped molecules. The strength of binding between a G-quartet and a non-planar circulene molecule depends on the orientation of the circulene (concave or convex) with respect to G-quartet. An AIM analysis of the M05-2X wave-functions has also been performed to confirm the presence of weak intermolecular interactions between guanine quartets and circulenes. Apart from $\pi$-stacking interactions, the concave bowl-shaped circulenes also interact with $\mathrm{G} 4$ through $\mathrm{C}-\mathrm{H} \cdot \cdots \pi$ interactions. The charge transport properties between the two moieties have also been analysed through effective transport integral. The calculations provide an understanding for the basis of molecular recognition by G4 for non-planar systems.
\end{abstract}

Keywords. $\pi$-Stacking; dispersion corrected DFT; DNA quadruplexes; circulenes; DNA intercalation complexes.

\section{Introduction}

Understanding the interactions between small organic ligands and DNA at the molecular level is important for the design of new drugs and probes that can recognize specific DNA sequences and structural motifs. ${ }^{1}$ Small molecules can interact with DNA by covalent or non-covalent ${ }^{2}$ groove binding, intercalation, or nonspecific binding along the DNA exterior. ${ }^{3}$ Structural perturbations ${ }^{4}$ caused by the induction of an intercalator, can lead to changes in the biological functions, making intercalators potent antitumor drugs and antiseptics. Intercalation with $\mathrm{DNA}^{5}$ by polycyclic, aromatic, and planar ${ }^{6,7}$ ligands can be considered as a specific case of aromatic stacking interaction, where the dispersion forces play an important role. A wide range of chemotherapeutic drugs like doxorubicin, ${ }^{8}$ daunorubicin, dactinomycin intercalate within DNA sequences.

DNA quadruplexes found in telomeres play important biological roles, interact with a number of proteins and are considered to be potential therapeutic targets against cancer. ${ }^{9,10}$ The building block of the quadruplex is the guanine quartet, characterized by four in-plane guanine bases, hydrogen bonded together in a cyclic arrangement. ${ }^{11}$ Molecules can interact with the G-quadruplexes by face recognition through stacking, edge recognition through $\mathrm{H}$-bonding and, loop or groove recognition through $\mathrm{H}$-bonding and electrostatic interactions. ${ }^{12}$ Stacking interactions are very important in controlling the structure and molecular recognition of G-quadruplex DNA. Aromatic compounds, such as other nucleobase assemblies or small molecule ligands can interact with the extended surface provided by the G-quartet. The stabilization resulting from aromatic stacking has been attributed to van der Waals dispersive forces (dipole-induced dipole and induced dipole-induced dipole attractions), permanent electrostatic effects of interacting dipoles and hydrophobic effect. ${ }^{13,14}$ Small molecules can generate G-quadruplex aptamers or stabilize the G-quadruplex DNA, thus influencing telomerase inhibition, which can kill cancer cells. The stacking of various aromatic ligands such as acridines, ${ }^{15}$ telomestatin, ${ }^{16}$ daunomycin. ${ }^{17}$ perylene derivatives ${ }^{18}$ anthraquinone derivatives, ${ }^{17}$ and porphyrins ${ }^{19}$ have been studied experimentally as well as by molecular dynamics. ${ }^{20,21}$

\footnotetext{
${ }^{*}$ For correspondence
} 


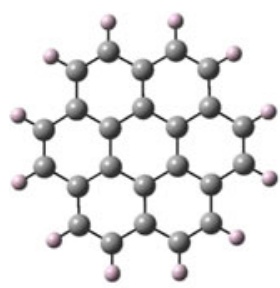

(a)

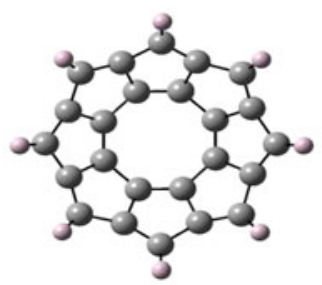

(b)

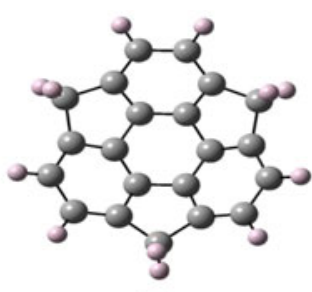

(c)

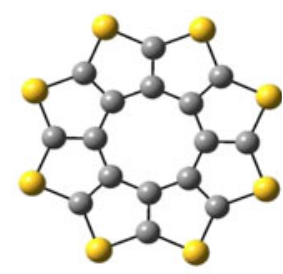

(d)

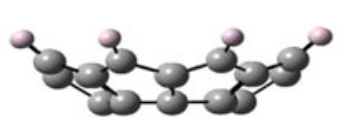

(e)

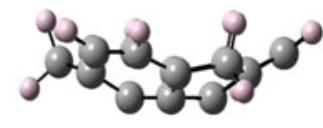

(f)

Figure 1. Optimized structures of (a) coronene $\left(\mathrm{D}_{6 h}\right)$, (b) 8-circulene $\left(\mathrm{C}_{4}\right)$, (c) sumanene $\left(\mathrm{C}_{3 v}\right),(\mathbf{d})$ sulflower $\left(\mathrm{D}_{8 h}\right),(\mathbf{e})$ 8-circulene (lateral view), and (f) sumanene (lateral view).

We have studied the $\pi$-stacking interactions between G-quartet and circulenes. Circulenes are a rare class of polyaromatic compounds built from arenes annulated into macrocycles, which can be viewed as fragments of fullerenes. ${ }^{22}$ Coronene ([6]-circulene), the only planar benzenoid circulene, has attracted significant attention as a guest molecule in two-dimensional molecular networks, and has been used as a building block for surface nanotemplates and sensor fabrication. ${ }^{23}$ Heterocirculenes, such as octathio[8]circulene (sulflower), have been predicted to have a future use as an electron donor in organic FET's and other materials science applications. ${ }^{24}$ In order to study such interactions, we have considered two planar circulenes-coronene and octathio[8]circulene, popularly called sulflower, as well as two bowl-shaped circulenes-sumanene ${ }^{25}$ and 8circulene (figure 1). There have been numerous experimental $^{26,27}$ and theoretical studies ${ }^{28,29}$ carried out on intercalation systems. Mostly, the calculations are based on empirical or semi-empirical methods and there are only a few $a b$ initio studies. ${ }^{30,31}$ However in the last decade, Density Functional Theory (DFT) has been widely accepted as a useful tool for understanding and predicting the electronic properties of new molecules and materials. Thus, we have carried out high level DFT calculations inclusive of dispersion interactions to study the stacking of circulenes over G-quartets.

\section{Computational methods}

The geometries of all monomers-sulflower, coronene, sumanene, 8-circulene and G-quartet were optimized at the B3LYP/6-31+G(d,p $)^{11,32}$ level using Gaussian 03. ${ }^{33}$ The G-quartet was modelled by replacing the sugar moiety by a $\mathrm{H}$-atom. We note that such truncations are commonly used in the literature. ${ }^{34}$ Standard DFT methods are often a better choice for large-sized systems as compared to quantum chemical methods such as MP2 or CCSD (T), because of the computational cost. DFT methods are efficient and typically have sufficient accuracy. Nevertheless, for van der Waals complexes, where the dispersion energy is important, even popular hybrid density functionals like B3LYP are often inadequate. ${ }^{35}$ Thus, for calculating the binding energy of the stacked complexes, the monomers as well as the G-quartet/circulene stacks were optimized at the M05$2 \mathrm{X} / 6-31+\mathrm{G}(\mathrm{d}, \mathrm{p})^{11,32}$ level. M05-2X ${ }^{36}$ functional effectively incorporates long-range dispersion forces and has been shown to describe non-covalent stacking interactions accurately. ${ }^{32,35}$ For the G-quartet/circulene stack, the binding energy, $\Delta \mathrm{E}$ was determined by:

$\Delta E=E(\mathrm{G} 4 \cdots$ circulene $)-E(\mathrm{G} 4)-E$ (circulene)

where $E$ (G4 ‥circulene) is the energy of the G-quartet complex with circulene, $E$ (G4) is the energy of an isolated G-quartet and $E$ (circulene) is the energy of the optimized circulene molecule. Basis set superposition error (BSSE) corrections were calculated to obtain the corrected interaction energy by using the counterpoise correction procedure $(\mathrm{CP}){ }^{37}$

RI-DFTD calculations at BLYP/TZVPP level were also performed to account for dispersion interactions using TURBOMOLE 6.0, ${ }^{11,32}$ within the empirical correction formalism. For the RI-DFTD calculations done, the structures optimized at M05-2X/6-31+G(d,p) level were used as initial guesses. To generate stacked (faceto-face) heterodimers of G4 and circulene molecules, the monomers were aligned according to their centres of mass. Unlike the optimized structures of coronene and sulflower which are planar, the structure of 8-circulene and sumanene are bowl-shaped (figure 1). Thus, we 
have defined a convex and a concave face for both these non-planar circulenes, to generate the geometry of the G4/circulene (non-planar) stack.

The charge transfer integral for the electrons and holes in between the two molecules can be calculated by DFT using the fragment orbital approach implemented in ADF 2010.02. ${ }^{38}$ The wave function of a hole can be written as a linear superposition of the highest occupied molecular orbitals (HOMOs) on the individual monomers-G-quartet and circulene. The site energies and charge-transfer integrals were obtained from the ADF output where the molecular orbitals of the monomers ( $\phi_{i}$ fragment orbitals), are utilized as a basis in the calculations on a system consisting of two or more molecules. Thus, we can change the basis from an atomic orbital basis to the fragment orbital basis, where the fragment consists of atoms in a G-quartet or a circulene. The advantage of this method is that now the overlap matrix is evaluated as the overlap between molecular orbitals of individual monomers. The standard output of the ADF program provides the overlap matrix, $\mathbf{S}$, the eigenvector matrix, $\mathbf{C}$, and the eigenvalue matrix, $\mathbf{E}$, in the fragment orbital basis. Using the generalized unitary transformation $\left(h_{K S}=\right.$ SCEC ${ }^{-1}$ ) we can readily evaluate the matrix elements of the Kohn-Sham Hamiltonian, $\left\langle\phi_{i}\left|h_{K S}\right| \phi_{j}\right\rangle$. This procedure allows direct calculations of the charge-transfer integrals, including their signs, without invoking the assumption of zero spatial overlap. Therefore, it is not necessary to apply an external electric field to bring the site energies of different monomers into resonance. This methodology has been successfully used earlier to describe hole transfer in DNA stacks. ${ }^{39}$

The charge transfer integrals for the G4/circulene stacks were calculated with the generalized gradient approximation (GGA) at dispersion-corrected BLYP-D level with a TZ2P basis set. Dispersion corrected functionals, especially BLYP-D, ${ }^{40}$ have been shown to be well-suited for describing $\mathrm{H}$-bonded base pairs as well as stacked AT/GC dimers. The orbitals of the G4/circulene stack are expressed as the linear combination of the molecular orbitals of G4 and the circulene molecule and the charge transfer integral can be directly obtained as the off-diagonal matrix element

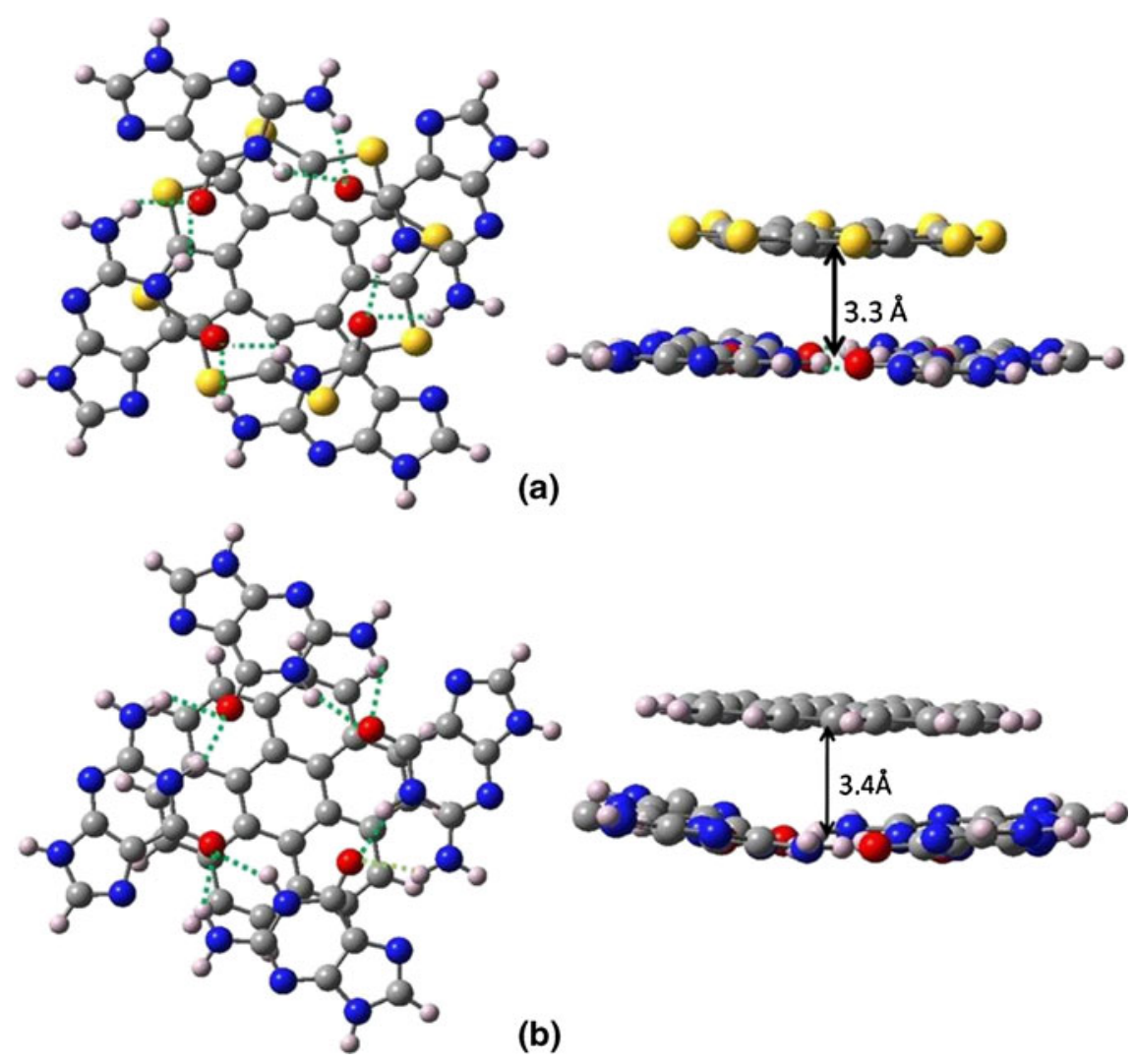

Figure 2. Optimized geometry of (a) G4/sulflower stack - top view and lateral view and (b) G4/coronene stack - top and lateral view [grey - carbon, white hydrogen, red - oxygen, blue - nitrogen, yellow - sulphur]. 
of the Kohn-Sham Hamiltonian matrix. The generalized or effective charge transfer $(V)$ is given by the following:

$$
V=t-\frac{1}{2} S\left(E_{1}+E_{2}\right)
$$

where $t$ is the charge transfer integral, $S$ is the spatial overlap and $E_{1}$ and $E_{2}$ are the site energies of two molecular orbitals where charges are localized.

The obtained wave-functions at the M05-2X/ $6-31+\mathrm{G}(\mathrm{d}, \mathrm{p})$ computational level have been used to analyse the electron density within the AIM methodology by AIM $2000^{41}$ package.

\section{Results and discussion}

The structures of circulenes are investigated at B3LYP/6-31+G(d,p) level. Sulflower and coronene are planar and are highly symmetric with $\mathrm{D}_{8 h}$ and $\mathrm{D}_{6 h}$ point group, respectively. Sumanene and 8-circulene is bowlshaped and their minimal energy structures have $\mathrm{C}_{3 v}$ and $\mathrm{C}_{4}$ point group, respectively. Optimized geometries for the bowls as well as the corresponding planar transition state structure were considered to estimate the barrier for bowl-to-bowl inversion. The inversion barrier for sumanene and 8-circulene was found to be $18.2 \mathrm{kcal} / \mathrm{mol}$ and $54.2 \mathrm{kcal} / \mathrm{mol}$, respectively. Experimentally, the inversion barrier for sumanene and its derivatives has been determined by ${ }^{1} \mathrm{H}$ NMR and 2D exchange spectroscopy (EXSY) NMR and are in the range of 19.7 to $20.1 \mathrm{kcal} / \mathrm{mol}^{42}$ Thus, DFT calculations are very effective to estimate the barrier height. Our calculations thus suggest that bowl-to-bowl inversion should be difficult in 8-circulene. The driving force for polycyclic aromatic hydrocarbons to adopt curved geometry is relief of strain from the planar form which has unusually large $\mathrm{C}-\mathrm{C}$ bond lengths. Therefore, the structures, which experience maximum strain in the planar form, have a greater tendency to pucker and thus, eventually their equilibrium bowl structures are more curved.

Further, the stacks of G-quartet and circulenes were optimized at M05-2X/6-31+G(d,p) level. For the planar circulenes - sulflower and coronene, only a single geometry for the stack exists (figure 2). Two different orientations (convex and concave) with respect to the G-quartet have been studied for the bowlshaped circulenes-sumanene and 8-circulene. Due to
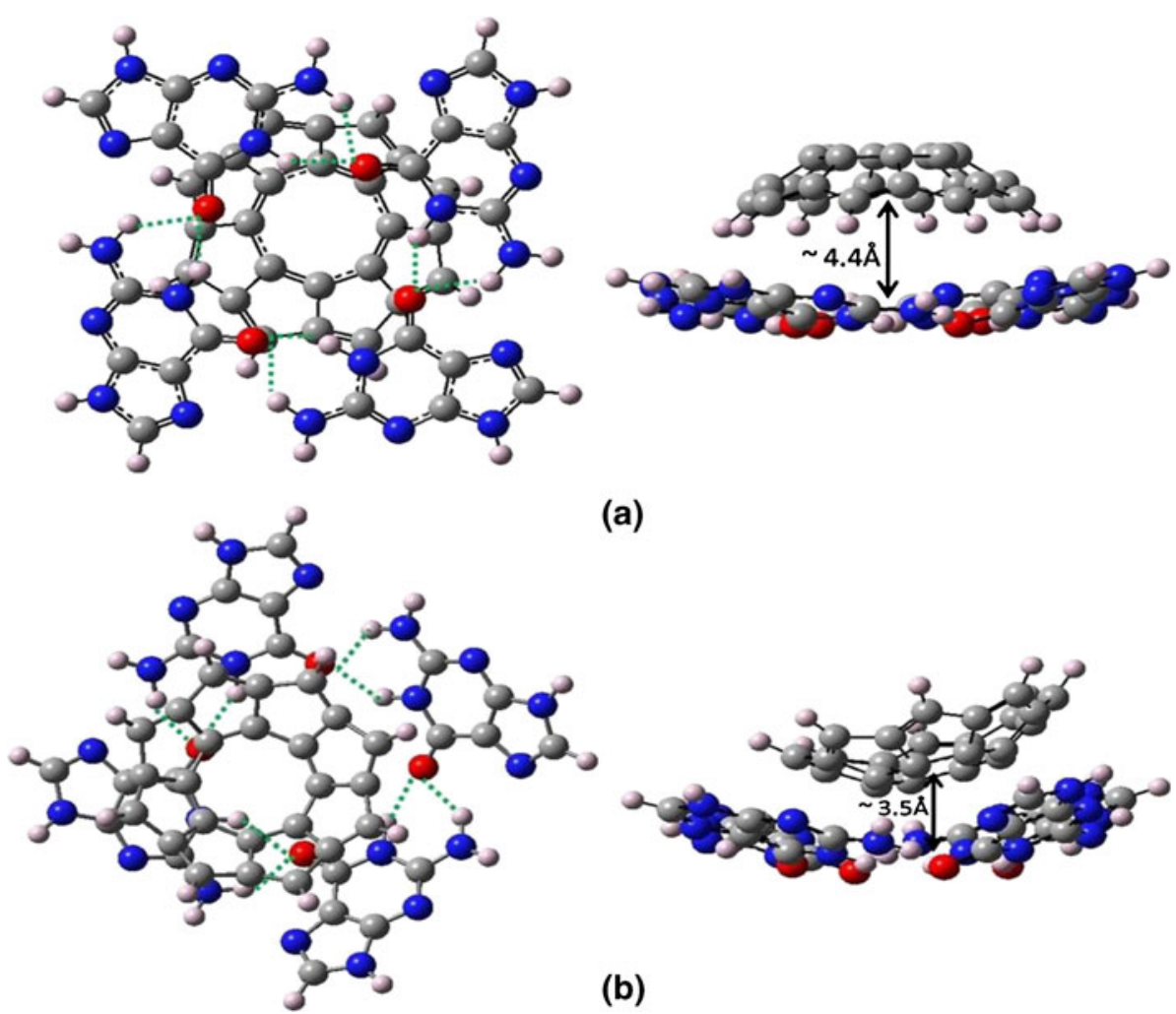

(a)

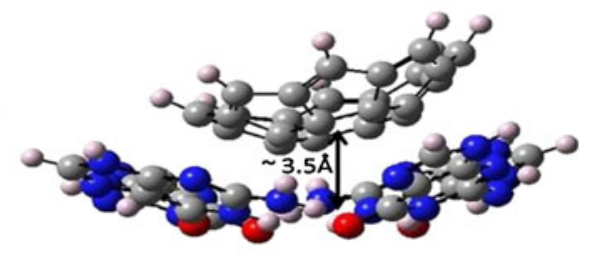

(b)

Figure 3. Optimized geometry of (a) G4/8-circulene (concave) stack-top view and lateral view and (b) G4/8-circulene (convex) stack-top and lateral view [grey carbon, white - hydrogen, red - oxygen, blue - nitrogen]. 


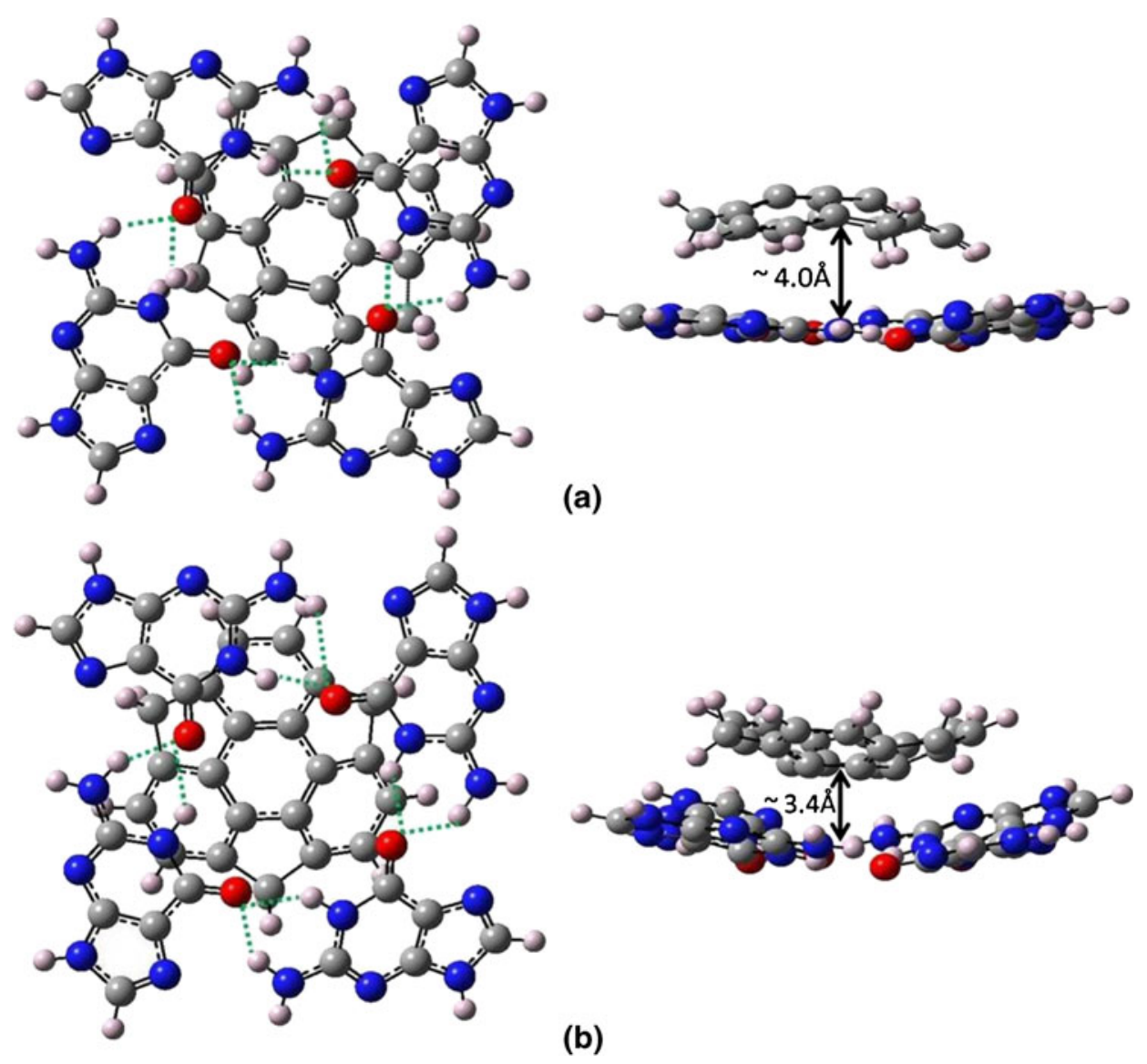

Figure 4. Optimized geometry of (a) G4/sumanene (concave) stack-top view and lateral view and (b) G4/sumanene (convex) stack-top and lateral view [grey - carbon, white - hydrogen, red - oxygen, blue - nitrogen].

the interaction of G4 with these two circulenes, oriented in the upward direction, the G-quartet drifts away from planarity and itself attains a bowl-shaped structure (figures 3 and 4). The deviation from planarity is much more profound in the case of 8-circulene as compared to sumanene. In the input geometries for stacked complexes, G-quartet stabilized by Hoogsteen H-bonding were used, which are known to stabilize
G-quadruplexes. The $\mathrm{N}-\mathrm{H}$ and the $\mathrm{O}-\mathrm{H}$ hydrogen bond distances in the isolated G-quartet are $1.8 \AA$ and $2.0 \AA$, respectively and the $\mathrm{O}-\mathrm{O}$ distance between two adjacent G-quartets is $3.5 \AA$. On interaction with the two different surfaces of bowl-shaped circulene molecules, the structural parameters tend to differ from each other. On complexation, the quartet is no longer stabilized by Hoogsteen $\mathrm{H}$-bonding, but instead by four

Table 1. Binding energies (in kcal/mol) and effective charge transfer integrals of G4/circulene stacks.

\begin{tabular}{|c|c|c|c|c|}
\hline \multirow[t]{2}{*}{ Molecule } & \multirow[t]{2}{*}{$\begin{array}{c}\text { B.E. }(\mathrm{kcal} / \mathrm{mol}) \\
\text { M05-2X/ 6-31+G(d,p) }\end{array}$} & \multirow[t]{2}{*}{$\begin{array}{c}\text { B.E. (kcal/mol) } \\
\text { (RI-DFTD) BLYP/TZVPP }\end{array}$} & \multicolumn{2}{|c|}{$\begin{array}{c}\text { Effective charge transfer } \\
\text { integrals }(\mathrm{eV}) \text { BLYP-D/TZ2P }\end{array}$} \\
\hline & & & $\mathrm{V}^{\text {eff }}$ (hole) & $\mathrm{V}^{\mathrm{eff}}$ (electron) \\
\hline G4-sulflower & $-22.9(-16.3)$ & -23.2 & 0.00357 & -0.06592 \\
\hline G4-coronene & $-18.3(-13.8)$ & -26.2 & -0.04256 & -0.01124 \\
\hline G4-sumanene (convex) & $-14.6(-9.98)$ & -20.9 & 0.00778 & -0.06706 \\
\hline G4-sumanene (concave) & $-13.8(-10.9)$ & -19.7 & -0.01163 & 0.03725 \\
\hline G4-8-circulene (convex) & $-16.3(-10.7)$ & -28.5 & 0.06040 & 0.02581 \\
\hline G4-8-circulene (concave) & $-14.2(-11.1)$ & -27.0 & -0.00193 & 0.02409 \\
\hline
\end{tabular}

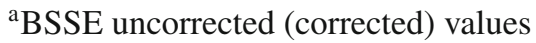


pairs of bifurcated H-bonds in all stacked complexes. In the complexes formed with concave faced circulenes as well as the planar circulenes, the $\mathrm{O}-\mathrm{H}$ and the $\mathrm{O}-\mathrm{O}$ bond distances are $1.95 \AA-2.0 \AA$ and $4.2 \AA$, respectively. However, on interaction with convex faced circulenes, the $\mathrm{O}-\mathrm{H}$ and the $\mathrm{O}-\mathrm{O}$ bond distances are 2-2.1 $\AA$ and $4.4 \AA$, respectively, and are thus comparatively longer. In addition, in 8-circulene complexes, the dihedral angle between C6-N6 and N7-C8 of adjacent guanines is $136^{\circ}$ for 3 (a) whereas the value varies from $100^{\circ}$ to $120^{\circ}$ for $3(\mathrm{~b})$ (figure 3 ). The elongation in bonds as well as the larger deviation from planarity in convex faced circulenes complexes show that the two faces of bowl shaped circulenes interact with G-quartets in a different manner. For the planar circulenes, the dihedral angles for sulflower and coronene complex are $173^{\circ}$ to $179^{\circ}$ and $145^{\circ}$ to $165^{\circ}$, respectively, showing that the deviation from planarity is much lesser in these complexes. In case of both 8-circulene and sumanene, the binding of G-quartet with the circulenes oriented with their convex face towards the G-quartet is stronger, irrespective of the G4 structure deviating more from planarity. Thus, G-quartet is capable of differentiating between the two orientations of non-planar circulenes. The effective charge transfer integrals also have been calculated for all stacked complexes. These values are indicative of the efficiency of charge transfer between two monomers. Siebbeles and co-workers have shown that the effective charge transfer integrals (hole) for nucleobases stacked at $3.38 \AA$ varies from $0.004 \mathrm{eV}$ to $0.1 \mathrm{eV} .^{39}$ Pati et al. have determined the generalized charge transfer integrals for fluctuations in AT-GC and GC-AT dinucleotide steps, and they have found values to vary between 0.001 and $0.01 \mathrm{eV}^{43}$ Our calculated values are well within this range of values obtained for stacked nucleobases. We also observe that the magnitude of $\mathrm{V}^{\text {eff }}$ is higher for complexes involving the convex face of circulenes interacting with G-quartet, particularly for the 8-circulene complexes. This indicates that the efficiency of charge transfer is much better in these complexes. The binding energies and the effective charge transfer integrals for all the complexes with G4 are reported in table 1.

The stacking distance between the non-planar circulenes and G-quartet has been determined as the average distance of the rim and the hub atoms from the quartet. The planar circulenes and the convex faced nonplanar circulenes stack at a distance of about $3.4 \AA$

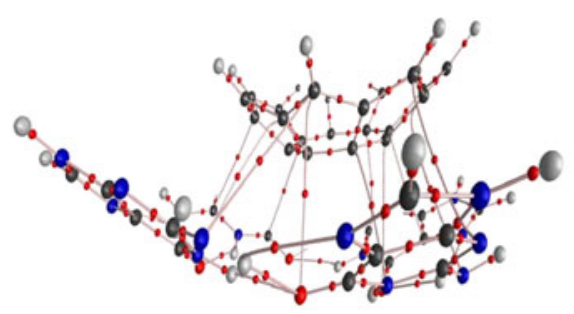

(a)

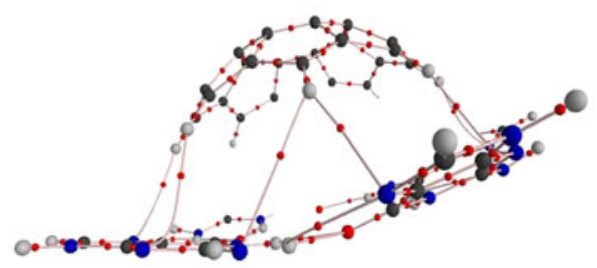

(b)
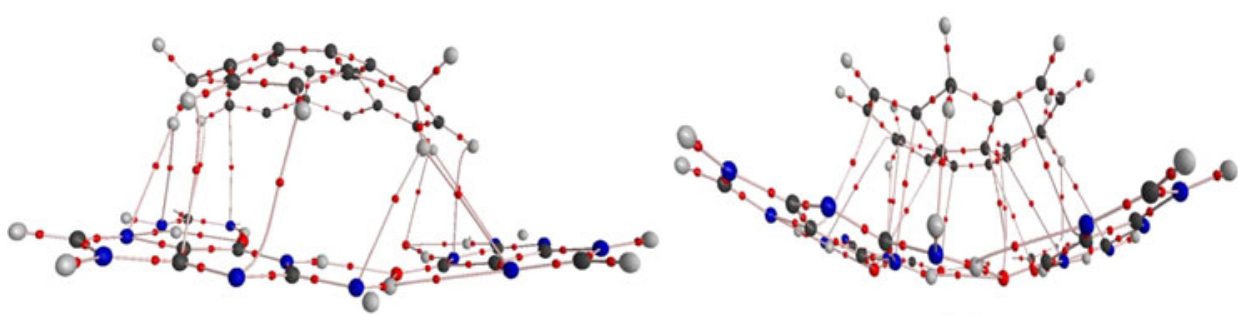

(c)

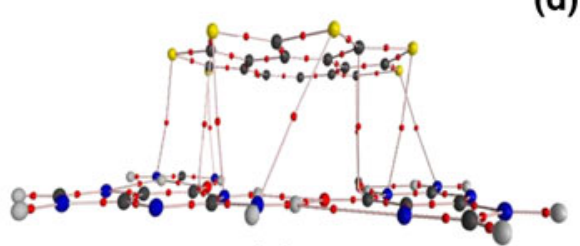

(d)

(e)

Figure 5. Location of bond critical points in (a) G4/8-circulene (convex), (b) G4/8circulene (concave), (c) G4/sumanene (concave), (d) G4/sumanene (convex) and (e) G4/sulflower [grey - carbon, white - hydrogen, red - oxygen, blue - nitrogen, yellow sulphur]. 
with respect to the G-quartet. However, in the stacks, with the concave side of the bowl-shaped circulenes facing the G-quartet, the stacking distance increases to $4.0 \AA$ and $4.4 \AA$, in G4/sumanene and G4/8-circulene stack, respectively. The stacks of non-planar circulene over G4, with a concave orientation, further interact with each other through $\mathrm{C}-\mathrm{H} \cdot \cdots \pi$ interactions. The attraction between the $\mathrm{C}-\mathrm{H}$ bond and the $\pi$ system is called $\mathrm{C}-\mathrm{H} \cdots \pi$ interaction. ${ }^{44}$ During these two decades several experimental studies, which support the existence of the attraction, have been reported. ${ }^{45}$ The close contact was observed in stable conformations of a lot of molecules. Such interactions are orientation dependent. The rim $\mathrm{C}-\mathrm{H}$ groups are suitably oriented with respect to the aromatic rings of guanine bases, in the stacks of concave faced circulenes, to interact through $\mathrm{C}-\mathrm{H} \cdots \pi$ interactions. The average distance between the $\mathrm{C}-\mathrm{H}$ and the aromatic ring in $\mathrm{G} 4 /$ sumanene (concave) varies from $3.2 \AA$ to $4 \AA$, whereas in G4/8-circulene, this distance is about $3 \AA$. This, we believe might be a probable explanation for the higher stability of 8-circulene (concave) stack, compared to G4/sumanene (concave).

The initial geometries of all the stacks contained G4 with Hoogsteen type H-bonding, as it is well-known that in stacks, G-quartets are usually stabilized by such H-bonding. However, on structure optimization for all the stacks, G4 is further stabilized with four bifurcated H-bond pairs.

An AIM analysis of the M05-2X/6-31+G(d,p) wave function was performed to ascertain the bonding arising between circulenes and G-quartet. The AIM approach relies on an analysis of the topological properties of the charge density, $\rho(r)$ and its quality depends on the computational level chosen. ${ }^{46}$ Both the gradient and the Laplacian of the charge density, $\nabla \rho$ and $\nabla^{2} \rho$, respectively, can be analysed and which provide complementary information on bonds. The critical points of $\nabla \rho$ give information about the existence of bonds, while the sign of $\nabla^{2} \rho$ at that point reflects the kind of interaction, namely the Laplacian of the charge density. Nuclei attract the charge density so that maxima of $\rho$ are found there. A bond corresponds to a saddle point (the bond critical point), where $\rho$ becomes zero, a maximum only in one plane of space, and is found joining two trajectories of maximum $r$ along the space, towards the nuclei. ${ }^{44} \mathrm{~A}(3,-1)$ bond critical point is indicative of bonding between atoms. The number of bond critical points located between G-quartet and sulflower, sumanene (convex), sumanene (concave), 8-circulene (convex) and 8-circulene (concave) are 12, 16, 14, 11 and 10 , respectively and they are shown in figure 5 . Among these bonding components, in the G4-sulflower stack, eight are between $\mathrm{N}$ and $\mathrm{S}$, three between $\mathrm{C}$ and $\mathrm{C}$ and one between $\mathrm{O}$ and $\mathrm{C}$; in the $\mathrm{G} 4$-sumanene (convex) stack, six are between $\mathrm{N}$ and $\mathrm{C}$, two between $\mathrm{C}$ and $\mathrm{C}$, four between $\mathrm{O}$ and $\mathrm{C}$, two between $\mathrm{N}$ and $\mathrm{H}$ and two between $\mathrm{H}$ and $\mathrm{C}$; in the $\mathrm{G} 4$-sumanene (concave) stack, ten are between $\mathrm{N}$ and $\mathrm{H}$, two between $\mathrm{C}$ and $\mathrm{H}$ and two between $\mathrm{O}$ and $\mathrm{H}$; in the G4-8-circulene (convex) stack, five are between $\mathrm{N}$ and $\mathrm{C}$, four between $\mathrm{C}$ and $\mathrm{C}$ and two between $\mathrm{O}$ and $\mathrm{C}$ and in the G4-[8]circulene (concave) stack, all are between nitrogen of G4 and hydrogens of 8 -circulene. Electron density $(\rho)$ and Laplacian of density $\left(\nabla^{2} \rho\right)$ at the critical points were also calculated. $\rho$ and $\nabla^{2} \rho$ were in the range of $2 \times 10^{-3}$ to $9 \times 10^{-3}$ a.u. and $-7 \times 10^{-3}$ to $-2 \times 10^{-3}$ a.u., respectively. The Laplacian is negative for all the bond critical points suggesting non-covalent bonding interactions. In the structures represented by 5 (a) and 5 (b), for G4-[8]circulene complexes, the electron density varies from $3 \times 10^{-3}$ to

Table 2. Topological properties at bond critical point $(\mathrm{BCP})(3,-1)$ in the $\mathrm{G} 4-[8]$ circulene calculated at the M05-2X/6$31+\mathrm{G}(\mathrm{d}, \mathrm{p})$ level of theory.

\begin{tabular}{lccccc}
\hline $\begin{array}{l}\text { G4-[8]circulene } \\
\text { (convex) }\end{array}$ & $\rho$ (a.u.) $\times 10^{-3}$ & $\nabla^{2} \rho$ (a.u.) $\times 10^{-3}$ & $\begin{array}{c}\text { G4-[8] circulene } \\
\text { (concave) }\end{array}$ & $\rho($ a.u. $) \times 10^{-3}$ & $\nabla^{2} \rho($ a.u. $) \times 10^{-3}$ \\
\hline C-C & & & N-H & 7.7 & -6.4 \\
C-C & 6.8 & -7.2 & N-H & 5.9 & -4.9 \\
C-C & 8.5 & -6.7 & N-H & 2.3 & -1.9 \\
C-O & 9.2 & -5.9 & N-H & 7.7 & -6.4 \\
C-N & 5.6 & -4.3 & N-H & 5.7 & -4.5 \\
C-N & 2.8 & -2.2 & N-H & 7.3 & -6.2 \\
C-N & 7.6 & -5.3 & N-H & 7.7 & -4.8 \\
C-O & 4.6 & -3.1 & N-H & 2.4 & -2 \\
C-N & 4.9 & -3.7 & N-H & 7.8 & -6.5 \\
C-N & 3.9 & -2.5 & N-H & 5.6 & -4.7 \\
C-C & 7.7 & -5.4 & & & \\
\hline
\end{tabular}


Table 3. Topological properties at bond critical point $(\mathrm{BCP})(3,-1)$ in $\mathrm{G} 4$-sumanene calculated at the $\mathrm{M} 05-2 \mathrm{X} / 6-31+\mathrm{G}(\mathrm{d}$,p) level of theory.

\begin{tabular}{|c|c|c|c|c|c|}
\hline $\begin{array}{l}\text { G4-sumanene } \\
\text { (convex) }\end{array}$ & $\rho($ a.u. $) \times 10^{-3}$ & $\nabla^{2} \rho($ a.u. $) \times 10^{-3}$ & $\begin{array}{l}\text { G4-sumanene } \\
\text { (concave) }\end{array}$ & $\rho$ (a.u. $) \times 10^{-3}$ & $\nabla^{2} \rho$ (a.u. $) \times 10^{-3}$ \\
\hline $\mathrm{C}-\mathrm{C}$ & 5.4 & -3.4 & $\mathrm{~N}-\mathrm{H}$ & 3.5 & -2.9 \\
\hline $\mathrm{C}-\mathrm{O}$ & 4.1 & -3.3 & $\mathrm{~N}-\mathrm{H}$ & 6.0 & -5.0 \\
\hline $\mathrm{C}-\mathrm{N}$ & 3.1 & -2.1 & $\mathrm{C}-\mathrm{H}$ & 7.3 & -5.7 \\
\hline $\mathrm{C}-\mathrm{N}$ & 6.1 & -4.3 & $\mathrm{~N}-\mathrm{H}$ & 5.1 & -4.2 \\
\hline $\mathrm{N}-\mathrm{H}$ & 6.2 & -5.1 & $\mathrm{~N}-\mathrm{H}$ & 3.0 & -2.4 \\
\hline $\mathrm{C}-\mathrm{H}$ & 5.6 & -4.4 & $\mathrm{C}-\mathrm{H}$ & 5.7 & -5.4 \\
\hline $\mathrm{C}-\mathrm{O}$ & 6.1 & -4.8 & $\mathrm{C}-\mathrm{N}$ & 6.0 & -4.0 \\
\hline $\mathrm{C}-\mathrm{N}$ & 6.7 & -4.7 & $\mathrm{C}-\mathrm{H}$ & 6.0 & -5.4 \\
\hline $\mathrm{C}-\mathrm{O}$ & 6.4 & -5.1 & $\mathrm{O}-\mathrm{H}$ & 2.7 & -2.8 \\
\hline $\mathrm{C}-\mathrm{H}$ & 6.8 & -5.7 & $\mathrm{~N}-\mathrm{H}$ & 6.0 & -4.7 \\
\hline $\mathrm{C}-\mathrm{N}$ & 4.9 & -3.4 & $\mathrm{O}-\mathrm{H}$ & 3.5 & -3.2 \\
\hline $\mathrm{C}-\mathrm{N}$ & 7.1 & -4.9 & $\mathrm{~N}-\mathrm{H}$ & 2.6 & -2.2 \\
\hline $\mathrm{C}-\mathrm{C}$ & 5.8 & -3.5 & $\mathrm{~N}-\mathrm{H}$ & 7.4 & -5.9 \\
\hline $\mathrm{C}-\mathrm{O}$ & 6.7 & -5.3 & $\mathrm{~N}-\mathrm{H}$ & 5.1 & -4.2 \\
\hline $\mathrm{N}-\mathrm{H}$ & 7.0 & -5.2 & & & \\
\hline $\mathrm{C}-\mathrm{N}$ & 6.9 & -4.5 & & & \\
\hline
\end{tabular}

$9.2 \times 10^{-3}$ a.u. and from $2.3 \times 10^{-3}$ to $7.8 \times 10^{-3}$ a.u., respectively. Similarly, for sumanene complexes, for 5 (d) the electron density is higher than $6.5 \times 10^{-3}$ a.u. for six of the sixteen bond critical points whereas for 5 (c) only one BCP out of fourteen had a $\rho$ value exceeding $6.5 \times 10^{-3}$ a.u. Thus for both bowl-shaped circulenes, in convex faced molecules the electron density is higher for the bond critical points between the two monomers, representing stronger intermolecular interactions. The topological properties of the BCP's have been recorded in tables 2 and 3 . In the stacks of concave bowl-shaped circulenes, most of the bond critical points supporting the presence of non-covalent interactions with the quartet are between hydrogen atoms of circulenes and ring atoms of the four guanine bases. Particularly, for G4-8circulene (concave) all the $(3,-1)$ BCP's corresponding to the non-covalent interactions are between the hydrogens of rim $\mathrm{C}-\mathrm{H}$ of 8 -circulene and the ring nitrogens of guanine. This, further validates the stabilization of these complexes through $\mathrm{C}-\mathrm{H} \cdots \pi$ interactions.

The extent of non-covalent interactions can also be estimated from the non-zero effective transfer integral $\left(\mathrm{V}^{\text {eff }}\right)$ between the stacks. These are comparable to the values between the $\mathrm{A}-\mathrm{T}$ and $\mathrm{G}-\mathrm{C}$ H-bonded dimer. ${ }^{39}$

\section{Conclusion}

We have studied $\pi$-stacking interactions of planar and bowl-shaped circulenes with G-quartets using dispersion corrected DFT functionals. The G-quartet is stabilized by bifurcated $\mathrm{H}$-bonds on stacking with circulenes. Planar circulenes bind much more strongly to G-quartets as compared to their bowl-shaped counterparts. A deviation in planarity is observed in the G-quartet structure on interacting with circulenes oriented in the upward direction. AIM analysis shows the presence of strong non-covalent interactions as well as $\mathrm{C}-\mathrm{H} \cdot \cdot \pi$ interactions between G-quartets and circulenes. Interestingly, we find that G4 quartet is capable of differentiating between the concave and convex surfaces of sumanene and 8-circulene. We believe that this is an important result because this provides an atomistic picture of the basis of molecular recognition by biologically relevant systems like DNA and other nanostructures.

\section{Acknowledgements}

The authors thank the Department of Science and Technology (DST) - Fast Track scheme, Council of Scientific and Industrial Research (CSIR) and University Grants Commission (UGC) for partial funding.

\section{References}

1. (a) Baraldi P G, Bovero A, Fruttarolo F, Preti D, Tabrizi M A, Pavani M G and Romagnoli R 2004 Med. Res. Rev. 24, 475; (b) Denny W A 2001 Curr. Med. Chem. 8 533; (c) Barton J K, Goldberg J M, Kumar C V, Turro N J 1986 J. Am. Chem. Soc. 1082081 
2. (a) Chiang S Y, Welch J, Rauscher F J III, Beerman, T A 1994 Biochemistry 33 7033; (b) Marsch G A, Ward R L, Colvin M, Turteltaub K W 1994 Nucleic Acids Res. 22 5408

3. Richards A D, Rodgers A 2007 Chem. Soc. Rev. 36471

4. Bond P J, Langridge R, Jennette K W, Lippard S J 1975 Proc. Natl. Acad. Sci. USA 725825

5. (a) Denny W A, Baguley B, Neidle S, Waring M 1994 Br. J. Clinical Pharmacol. 37 103; (b) Li S, Cooper V R, Thonhauser T, Lundqvist B I, Langreth D C $2009 \mathrm{~J}$. Phys. Chem. B 11311166

6. Lerman L S 1961 J. Mol. Biol. 318

7. (a) Hazarika P, Bezbaruah B, Das P, Medhi O K, Medhi C 2011 J. Biophys. Chem. 2 153; (b) Mukherjee A, Lavery R, Bagchi B, Hynes J T 2008 J. Am. Chem. Soc. 1309747

8. Cutts S M, Nudelman A, Rephaeli A, Phillips D R 2005 IUBMB Life. 5773

9. Neidle S, Parkinson G N 2003 Curr. Opin. Struct. Biol. 13275

10. Han H, Hurley L H 2000 Trends Pharmacol. Sci. 21136

11. Jissy A K, Ashik U P M, Datta A 2011 J. Phys. Chem. C 11512530

12. Davis J T 2004 Angew. Chem., Int. Ed. 43668

13. Sponer J, Riley K, Hobza P 2008 Phys. Chem. Chem. Phys. 102595

14. (a) Meyer E A. Castellano R K, Diederich F 2003 Angew. Chem. 115 1244; (b) Meyer E A, Castellano R K, Diederich F 2003 Angew. Chem. Int. Ed. 421210

15. (a) Haider S M, Parkinson G N, Neidle S 2003 J. Mol. Biol. 326 117; (b) Moore M J, Schultes C M, Cuesta J, Cuenca F, Gunaratnam M, Tanious F A, Wilson W D, Neidle S 2006 J. Med. Chem. 49582

16. Kim M Y, Vankayalapati H, Kazuo S, Wierzba K, Hurley L H 2002 J. Am. Chem. Soc. 1242098

17. (a) Clark G R, Pytel P D, Squire C J, Neidle S 2003 J. Am. Chem. Soc. 125 4066; (b) Sun D Y, Thompson B, Cathers B E, Salazar M, Kerwin S M, Trent J O, Jenkins T C, Neidle S, Hurley L H 1997 J. Med. Chem. 402113

18. Fedoroff O Y, Salazar M, Han H, Chemeris V V, Kerwin S M, Hurley L H 1998 Biochem. 3712367

19. (a) Siddiqui-Jain A, Grand C L, Bearss D J, Hurley L H 2002 Proc. Natl. Acad. Sci. USA 99 11593; (b) Arthanari H, Basu S, Kawano T L, Bolton P H 1998 Nucleic Acids Res. 26 3724; (c) Han H Y, Langley D R, Rangan A, Hurley L H 2001 J. Am. Chem. Soc. 1236485

20. (a) Li M H, Luo Q, Xue X G, Li Z S 2011 J. Mol. Model. 17 515; (b) Hou J Q, Chen S B, Tan J H, Ou T M, Luo H B, Li D, Xu J, Gu L Q, Huang Z S 2010 J. Phys. Chem. B 11415301

21. (a) Cavallari M, Garbesi A, Di Felice R $2009 \mathrm{~J}$. Phys. Chem. B 113 13152; (b) Read M, Harrison R J, Romagnoli B, Tanious F A, Gowan S H, Reszka A P, Wilson W D, Kelland L R, Neidle S 2001 Proc. Natl. Acad. Sci. USA 984844

22. Dopper J H, Wynberg H 1975 J. Org. Chem. 401957

23. (a) Furukawa S, Tahara K, De Schryver F C, Van der Auweraer M, Tobe Y, De Feyter S 2007 Angew. Chem. Int. Ed. 46 2831; (b) Griessl S J H, Lackinger M, Jamitzky F, Market T, Hietschold M, Heckl W M 2004 Langmuir 20 9403; (c) Yoshimoto S, Tsutsumi E, Narita
R, Murata Y, Murata M, Fujiwara K, Komatsu K, Ito O, Itaya K 2007 J. Am. Chem. Soc. 129 4366; (d) Zhang H-X, Chen Q, Wen R, Hu J-S, Wan L-J 2007 Anal. Chem. 792179

24. (a) Datta A, Pati S K 2007 J. Phys. Chem. C (Lett.) 111 4487; (b) Dadvand A, Cicoira F, Chernichenko K Y, Balenkova E S, Osuna R M, Rosei F, Nenajdenko V G, Perepichka D F 2008 Chem. Comm. 42 5354; (c) Mohakud S, Pati S K 2009 J. Mater. Chem. 194356

25. (a) Sastry G N, Jemmis E D, Mehta G, Shah S R 1993 J. Chem. Soc., Perkin Trans. 2 1867; (b) Mehta G, Shah S R, Ravikumar K 1993 J. Chem. Soc. Chem. Commun. 12 1006; (c) Mehta G, Panda G 1998 PINSA-A: Proc. Indian Natl. Sci. Acad., Part. A 64587

26. (a) Berge T, Jenkins N S, Hopkins R B, Waring M J, Edwardson J M, Herderson R M 2002 Nucleic Acids Res. 30 2980; (b) Alonso A, Almendral M J, Curto Y, Criado J J, Rodrıguez E, Manzano J L 2006 Anal. Biochem. 355157

27. Shieh H S, Berman H M, Dabrow M, Neidle S 1980 Nucleic Acids Res. 885

28. (a) Tang P, Juang C L, Harbison G S 1990 Science 249 70; (b) Nuss M E, Marsh F J, Kollman P A 1979 J. Am. Chem. Soc. 101825

29. Trieb M, Rauch C, Wibowo F R, Wellenzohn B, Liedl K 2004 Nucleic Acids Res. 324696

30. Reha D, Kabelac M, Ryjacek F, Sponer J, Sponer J E, Elstner M, Suhai S, Hobza P 2002 J. Am. Chem. Soc. 1243366

31. Langner K M, Kedzierski P, Sokalski W A, Leszczynski J 2006 J. Phys. Chem. B $\mathbf{1 1 0} 9720$

32. Jissy A K, Datta A 2010 J. Phys. Chem. B 11415311

33. Frisch M J 2004 Gaussian 03; Gaussian, Inc.: Wallingford, CT

34. (a) Rutledge L R, Durst H F, Wetmore S D 2008 Phys. Chem. Chem. Phys. 10 2801; (b) Copeland K L, Anderson J A, Farley A R, Cox J R, Tschumper G S 2008 J. Phys. Chem. B 112 14291; (c) Rutledge L R, Durst H F, Wetmore S D 2009 J. Chem. Theory Comput. 51400

35. Zimmerli U, Parrinello M, Koumoutsakos P 2004 J. Chem. Phys. 1202693

36. (a) Zhao Y, Schultz N E, Truhlar D G 2006 J. Chem. Theory Comput. 2 364; (b) Hohenstein E G, Chill S T, Sherrill C D 2008 J. Chem. Theor. Comput. 41996

37. Boys S F, Bernardi F 1970 Mol. Phys. 19553

38. (a) te Velde G, Bickelhaupt F M, van Gisbergen S J A, Fonseca Guerra C, Baerends E J, Snijders J G, Ziegler T 2001 J. Comp. Chem. 22 931; (b) Fonseca Guerra C, Snijders J G, te Velde G, Baerends E J 1998 Theor. Chem. Acc. 99 391; (c) ADF2010, SCM, Theoretical Chemistry, Vrije Universiteit, Amsterdam, The Netherlands, http://www.scm.com

39. Senthilkumar K, Grozema F C, Guerra C F, Bickelhaupt F M, Lewis F D, Berlin Y A, Ratner M A, Siebbeles L D A 2005 J. Am. Chem. Soc. 12714894

40. Fonseca Guerra C, van der Wijst T, Poater J, Swart M, Bickelhaupt F M 2010 Theor. Chem. Acc. 125245

41. (a) Biegler König F W, Schöbohm J, Bayles D 2001 J. Comput. Chem. 22545 AIM2000; (b) Jose D, Datta A Cryst. Growth Des., Article ASAP DOI:10.1021/ cg200396v 
42. Amaya T, Sakane H, Muneishi T, Hirao T 2008 Chem. Comm. 6765

43. Mallajosyula S S, Gupta A, Pati S K 2009 J. Phys. Chem. A, 1133955

44. Nishio M, Hirota M, Umezawa Y 1998 The $C H / \pi$ interaction; New York: Wiley-VCH

45. (a) Iitaka Y, Kodama Y, Nishihata K, Nishio M 1974 J. Chem. Soc. Chem. Commun. 389; (b) Hirota M, Sekiya
T, Abe K, Tashiro H, Karatsu M, Nishio M, Osawa E 1983 Tetrahedron 39 3091; (c) Nakai Y, Yamamoto G, Oki M 1987 Chem. Lett. 89.

46. (a) Bader R F W 1990 Atoms in Molecules - A Quantum Theory, Oxford: Oxford Science; (b) Bader R F W 1991 Chem. Rev. 91 893; (c) Carroll M T, Chang C, Bader R F W 1988 Mol. Phys. 63 387; (d) Bone R G A, Bader R F W 1996 J. Phys. Chem. 10010892 